Artigo original

Hegemonia - Revista Eletrônica do Programa de Mestrado em Direitos Humanos, Cidadania e Violência/Ciência Política do Centro Universitário Unieuro

ISSN: 1809-1261

UNIEURO, Brasília, número 23, Janeiro a Junho de 2018, pp. 132-159.

Recebido em: 2/8/2017

Avaliado em: 11/9/2017

Aprovado em: 20/10/2017

\title{
DETERMINANTES DA EMIGRAÇÃO PARA PALMAS (TO)
}

\author{
Abraão Cavalcante Lima, ${ }^{1}$ Tito Belchior Silva Moreira, ${ }^{2}$ Fernando Antônio Ribeiro Soares, ${ }^{3}$ Paulo \\ Roberto Amorim Loureiro, ${ }^{4}$ e George Henrique de Moura Cunha ${ }^{5}$
}

RESUMO: Este artigo discute os motivos que levam as pessoas a migrar para Palmas, discutindo tanto aspectos microeconômicos quanto aspectos macroeconômicos. Primeiramente, nós fazemos uma discussão teórica da economia da migração nos aludidos aspectos micro e macroeconômicos. Posteriormente, por meio de pesquisa junto a uma amostra populacional buscou-se identificar os fatores que afetaram a decisão de empreender a migração. Além de diversas questões socioeconômicas e demográficas, avaliou-se o quanto a questão financeira é fundamental para a decisão de emigrar. Os resultados empíricos mostram que a melhoria da qualidade de vida, emprego e a questão salarial são fatores determinantes para a migração.

\footnotetext{
${ }^{1}$ Doutor em Economia e professor do Centro Universitário Planalto do DF.

${ }^{2}$ Doutor em Economia e professor da Universidade Católica de Brasília.

3 Doutor em Economia e professor da Universidade Católica de Brasília.

${ }^{4}$ Doutor em Economia e professor da Universidade Católica de Brasília.

${ }^{5}$ Doutor em Economia e professor da Universidade Católica de Brasília.
} 
Artigo original

Hegemonia - Revista Eletrônica do Programa de Mestrado em Direitos Humanos, Cidadania e Violência/Ciência Política do Centro Universitário Unieuro

ISSN: 1809-1261

UNIEURO, Brasília, número 23, Janeiro a Junho de 2018, pp. 132-159.

PALAVRAS-CHAVES: determinantes da migração; Palmas; perfil do migrante; economia da migração.

ABSTRACT: This article discusses the reasons that lead people to migrate to Palmas, taking into account microeconomic and macroeconomic aspects. First, we make a theoretical discussion of the economics of migration in the aforementioned micro and macroeconomic aspects. Later, through survey of a population sample we sought to identify factors that affected the decision to undertake a migration. In addition to various socioeconomic and demographic issues, we assessed how the financial issue is fundamental to the decision to emigrate. The empirical results show that improving the quality of life, employment and the wage issues are determining factors for migration. KEYWORDS: determinants of migration; Palmas; profile of the migrant; economics of migration.

\section{Introdução}

Migração é a movimentação de pessoas de um lugar para outro, de forma permanente. A migração pode ser internacional (entre países diferentes) ou interna (dentro de um país, muitas vezes, das áreas rurais para as áreas urbanas). As motivações são as mais variadas. Vão desde a busca de um melhor padrão de vida e de melhores oportunidades à fuga de conflitos e da pobreza. Podemos resumir as motivações para as migrações como econômicas, sociais, políticas (inclusive religiosas e étnicas) e ambientais.

Num movimento migratório é importante considerar os impactos sobre o lugar deixado, bem como o local que receberá o migrante. No local deixado há uma diminuição da pressão populacional e do desemprego, o que se traduz em um alívio para a economia local. Também é diminuída a demanda pelos recursos naturais, o que é ambientalmente desejável. Além disso, há o benefício monetário em termos dos recursos transferidos a esta localidade pelos emigrantes. Por outro lado, o processo também apresenta desvantagens. As desvantagens associam-se, principalmente, à perda de 
Artigo original

Hegemonia - Revista Eletrônica do Programa de Mestrado em Direitos Humanos, Cidadania e Violência/Ciência Política do Centro Universitário Unieuro

ISSN: 1809-1261

UNIEURO, Brasília, número 23, Janeiro a Junho de 2018, pp. 132-159.

mão-de-obra, em especial da qualificada. O benefício, no nível do indivíduo, está associado fundamentalmente às melhores condições de emprego e renda, mas, por outro lado, pode vir junta com uma maior precarização ou mesmo ilegalidade deste trabalho. ${ }^{6}$

Voltando-se para a discussão do presente trabalho, a emigração para Palmas, temos que este Município, segundo dados do Instituto Brasileiro de Geografia (IBGE), tinha população estimada de 242.070 em 2012 contra 228.332, declarados no censo demográfico de 2010. O crescimento nesse período foi acima de 5\% enquanto o crescimento brasileiro foi de aproximadamente $1,7 \%$. Um dos principais fatores que explicam essa forte variação populacional é a emigração. ${ }^{7}$

O objetivo do presente artigo é justamente este: conhecer as motivações que levam as pessoas a migrar para o Município de Palmas - TO, tanto em termos microeconômicos quanto em termos macroeconômicos. Também é relevante identificar o perfil do emigrante, bem como a idade e o nível educacional. Ainda identificando os fatores associados à emigração para Palmas, e assim entender a própria dinâmica da cidade, pretende-se conhecer a origem das pessoas e as questões salariais correlatas à emigração. Restou comprovado que os fatores associados à melhoria da qualidade de vida, empregabilidade e a questão salarial foram fundamentais na decisão de emigrar, sendo isto constatado a partir de uma análise empírica construída a partir de uma amostra populacional da cidade.

Isto posto, segue a estrutura do artigo. $\mathrm{Na}$ primeira seção discute-se a teoria atinente à chamada "economia da migração", tanto em seus aspectos microeconômicos quanto nos macroeconômicos. Na segunda seção constrói-se o modelo estatístico/econométrico a ser utilizado no presente trabalho. Em especial, discutiu-se a metodologia do Probit, bem como o Modelo de Heckman. A terceira seção foi dedicada a apresentação dos dados e das variáveis utilizadas, bem como para detalhar algumas estatísticas descritivas obtidas a partir da amostra populacional. A quarta

\footnotetext{
${ }^{6}$ Há diversos aspectos sociais associados ao processo migratório, que, no entanto, não serão tratados no presente artigo, sendo uma excelente agenda de trabalho futuro.

7 Um dos fatores que explicam esta migração para Palmas é a ocorrência de concursos públicos.
} 
Artigo original

Hegemonia - Revista Eletrônica do Programa de Mestrado em Direitos Humanos, Cidadania e Violência/Ciência Política do Centro Universitário Unieuro

ISSN: 1809-1261

UNIEURO, Brasília, número 23, Janeiro a Junho de 2018, pp. 132-159.

seção apresenta a análise dos resultados dos modelos estimados. E, finalmente, na quinta seção estão as principais conclusões.

\section{Efeitos da Migração e a Economia da Migração}

Ravenstein (1885) pode ser considerado um dos pioneiros na discussão sobre migração. Anunciou leis gerais que regiam as migrações a partir da análise dos dados dos censos ingleses de 1871 e 1881. Com base nas suas pesquisas, chegou às seguintes leis: (i) a maioria dos migrantes deslocam-se para curtas distâncias e, normalmente, para cidades maiores; (ii) as cidades de crescimento rápido são povoadas por pessoas de regiões rurais fronteiriças; (iii) o processo de dispersão é o inverso do processo de absorção; (iv) o processo de migração gera uma corrente de compensação; (v) os migrantes de regiões distantes tendem a ser mover para cidades maiores; (vi) a população rural, quando comparada com a urbana, apresentam uma maior propensão a migrar; e (vii) as mulheres apresentam uma maior propensão a migrar.

Continuando a discussão, particularmente em seus aspectos microeconômicos, temos que o migrante é um indivíduo racional que decide migrar a partir de um cálculo de custos e benefícios. Caso os benefícios sejam superiores aos custos, gerando um retorno esperado positivo, a migração será realizada porque aumentará a utilidade do indivíduo. Ainda buscando maximizar sua utilidade, o indivíduo buscará migrar para locais onde suas habilidades sejam consideradas mais produtivas [Sjaastad (1962) e Todaro (1969)]. Harris e Todaro (1970) avançam no conceito, afirmando que os movimentos migratórios não são provocados apenas por diferenças salariais entre regiões, mas também pela existência de diferenciais de taxas de desemprego. Caso não houvesse diferenciais salariais e de desemprego não haveria movimento migratório.

Borjas (1989) enfatiza a existência de um mercado de migração entre os países receptores, que competiriam entre si, por meio de políticas públicas de imigração, para captar capital humano. Também considera que mudanças nos níveis de atividade econômica têm impactos nos fluxos 
Artigo original

Hegemonia - Revista Eletrônica do Programa de Mestrado em Direitos Humanos, Cidadania e Violência/Ciência Política do Centro Universitário Unieuro

ISSN: 1809-1261

UNIEURO, Brasília, número 23, Janeiro a Junho de 2018, pp. 132-159.

migratórios, afetando a oferta feita pelos países. Outra consideração de Borjas direciona-se para os indivíduos. $\mathrm{Na}$ busca da maximização de renda, os deslocamentos ocorrerão das regiões de baixa para as de elevada renda. Porém, isso ocorrerá caso os custos de deslocamentos forem inferiores ao diferencial de renda a ser obtido. No entanto, Borjas (1989) e Becker (1993) sinalizam que a renda do migrante tenderá ser menor que a dos nativos. Tal situação leva a esses migrantes a investir em capital humano.

Stark e Bloom (1985), Stark e Teylor $(1989,1991)$ e Teylor (1986) observam que a decisão de emigrar não é tomada isoladamente pelo indivíduo, mas influenciada pelo conjunto de pessoas a ele ligado. Dessa forma, muda-se o foco em relação à tradicional teoria microeconômica neoclássica, centrada na decisão do indivíduo maximizador. Os custos e os retornos são mensurados considerando todos os indivíduos afetados pela migração e não apenas o indivíduo emigrante. De outra forma, a condição socioeconômica do domicílio importa na decisão de emigrar. Assim, indivíduos migrariam para outras regiões caso a posição do domicílio melhorasse com o deslocamento.

Esta ideia também é apoiada por Mincer (1978), que coloca a decisão de migrar não apenas nos ganhos do indivíduo, mas nos ganhos e custos da família. Harbison (1981) também enfatiza o contexto familiar, onde a decisão de migrar é tomada exatamente dentro deste ambiente e com todas as suas relações envolvidas. Além disso, observa que a dispersão geográfica familiar, ao propiciar maior disponibilidade de informações, aumenta a expectativa de sucesso do processo migratório. Tem-se aí reforçado o papel das redes sociais.

Adentrando em alguns aspectos macroeconômicos, do ponto de vista neoclássico, Lewis (1954) e Ranis e Fei (1961) explicam a migração pelas diferenças geográficas de oferta e demanda por trabalho. O mercado de trabalho induziria aos movimentos migratórios. Onde houvesse excesso de oferta de trabalho, os salários seriam baixos, e vice-versa. Assim, o deslocamento ou migração ocorreria das regiões marcadas pelo excesso de oferta de mão-de-obra (e baixos salários) para as regiões com escassez de mão-de-obra (e elevados salários). Com a intensificação dos fluxos 
Artigo original

Hegemonia - Revista Eletrônica do Programa de Mestrado em Direitos Humanos, Cidadania e Violência/Ciência Política do Centro Universitário Unieuro

ISSN: 1809-1261

UNIEURO, Brasília, número 23, Janeiro a Junho de 2018, pp. 132-159.

migratórios, tenderia a ocorrer uma diminuição dos desequilíbrios entre a oferta e a demanda de mão-de-obra entre as regiões (ou países), bem como do diferencial salarial. No limite seria eliminada a diferença entre os salários e a migração cessaria.

O papel das redes sociais também tem sido destacado nos estudos sobre migração [Harbison (1981), Massey (1990), Massey et al. (1987) e Massey et al. (1993)]. De acordo com esta vertente, as redes sociais teriam um importante papel na perpetuação dos fluxos migratórios. Detalhando, as redes sociais trazem informações sobre a rede migratória. Tais informações, por seu turno, reduzem os custos e os riscos do deslocamento e, além disso, aumentam a expectativa de retorno com a migração. Dessa forma, tanto quanto diferenças salariais ou de emprego, as redes sociais entre os migrantes geram um forte estímulo ao processo migratório. Na mesma linha, Fawcett (1989) destaca o papel das redes de parentesco, onde o fluxo de informação entre parentes também estimularia o processo migratório.

Piore (1979), ao analisar o mercado de trabalho, aponta que a migração internacional é algo inerente à estrutura econômica dos países desenvolvidos. Seu principal elemento motivador seria a constante demanda pelo trabalho de migrantes nesses países. Em síntese, a migração não seria causada por fatores de expulsão nos países de origem, mas por fatores de atração nos países de destino. Os fluxos migratórios seriam estabelecidos a partir do recrutamento de mão-de-obra nos países em desenvolvimento para atender às necessidades dos empregadores nos países desenvolvidos.

Conclui-se, portanto, que a decisão de um indivíduo migrar está relacionada a diversos fatores, especialmente, à melhoria da qualidade de vida. Colocando de outra forma, procura-se um padrão de bem-estar mais alto, seja ele em termos salariais, de alimentação, de segurança, de educação etc., sendo isso relevante tanto para migrações externas quanto internas.

3. Modelo de Determinação da Migração para Palmas - TO

A contribuição das regiões brasileiras na formação da população de Palmas, segundo dados do Censo Demográfico do IBGE para o ano de 2010, foi capitaneada pela própria Região Norte 
Artigo original

Hegemonia - Revista Eletrônica do Programa de Mestrado em Direitos Humanos, Cidadania e Violência/Ciência Política do Centro Universitário Unieuro

ISSN: 1809-1261

UNIEURO, Brasília, número 23, Janeiro a Junho de 2018, pp. 132-159.

com 56,7\% dos imigrantes. A Região Nordeste contribuiu com 21,5\%, destacando-se o Estado do Maranhão. As demais regiões, Sudeste, Sul e Centro-Oeste, contribuíram, respectivamente, com, aproximadamente, $5,9 \%, 2,2 \%$ e 12,6\%. Claramente se destaca a migração interna e, logo em seguida, a migração das regiões fronteiriças. Ainda segundo dados do IBGE, Palmas foi a capital com a maior taxa de crescimento anual da população (5,21\%), muito em função da migração.

Feitas estas considerações quantitativas da evolução populacional de Palmas, é importante identificar as variáveis relevantes na determinação de um processo migratório. A variável idade e nível de educação identificam o perfil do migrante e influencia na decisão de migrar. Verifica-se, além disso, que os jovens do sexo masculino são mais propensos a migrar. O IPEA, em um estudo datado de 2010, analisou o efeito da distribuição de renda e das transferências federais sobre o fluxo migratório no Brasil. Concluiu-se que as transferências têm efeito positivo no fluxo migratório. Além disso, também foi verificado que a concentração de renda também estimula a migração, com os migrantes buscando regiões com distribuição mais equitativa da renda. Outra consideração importante é que os fluxos migratórios no Brasil se modificaram nas últimas décadas. Retenção da população no Nordeste, baixa atratividade pelo Estado de São Paulo e maior fluxo para as cidades médias são algumas das características. Dentre estas cidades médias, se destaca Palmas.

Estas informações são importantes para balizar os testes que serão apresentados no presente artigo. A metodologia seguirá um modelo de escolha discreta, que permite verificar a probabilidade de um indivíduo, dado um conjunto de características pessoais, familiares, econômicas e de interação social, de migrar. Para tanto, utilizar-se-á o Modelo de Heckman de dois estágios. ${ }^{8}$ A discussão terá início com a equação comportamental do Probit.

\footnotetext{
${ }^{8}$ No primeiro estágio estima-se um Probit. No segundo estágio estima-se um mínimo quadrado ordinário para a equação controlando-se pela razão inversa de Mills em cada equação.
} 
Artigo original

Hegemonia - Revista Eletrônica do Programa de Mestrado em Direitos Humanos, Cidadania e Violência/Ciência Política do Centro Universitário Unieuro

ISSN: 1809-1261

UNIEURO, Brasília, número 23, Janeiro a Junho de 2018, pp. 132-159.

\section{Modelo Probit: Equação Comportamental}

No Probit a variável a ser explicada é a escolha dicotômica: emigrar ou não emigrar como variável dependente. As variáveis que incorporam esta identificação (emigrar ou não emigrar) geralmente não são diretamente observáveis para cada característica $i$. Pode-se, então, definir $y^{*}$ como um estado (não observável) latente. Para prever a probabilidade de um indivíduo vir a ser um emigrante, será estimado o seguinte Probit:

$$
y_{i}^{*}=\beta_{i} X_{i k}+\mu_{i} \text {, onde } i=1, \ldots, \mathrm{n}
$$

$\mathrm{Na}$ equação acima, $X_{i k}$ representa um conjunto de variáveis explicativas relacionadas ao indivíduo. A variável $y$ representa a variável dummy, onde $y=1$ e $y=0$ representam, respectivamente, as decisões de emigrar e não emigrar. $\mathrm{O}$ parâmetro $\beta_{i}$, como não poderia ser diferente, mede o efeito de mudanças nas variáveis explicativas $\left(X_{i k}\right)$ sobre a variável latente (não observável) $y_{i}^{*}$.

Ainda sobre os efeitos das variáveis explicativas sobre a variável latente, é importante observar que a interpretação dar-se-á meramente de forma ordinal, não havendo uma interpretação cardinal. Assim, um sinal positivo no coeficiente da variável explicativa aumenta a probabilidade de um indivíduo migrar, e vice-versa. Também é relevante trazer considerações adicionais para a variável não observável. Quanto maior o valor de $y_{i}^{*}$, maior a probabilidade de o indivíduo emigrar. Além disso, $y_{i}^{*}$ é não observável, mas pode ser identificado, tomando valores entre 0 e 1 . Com isso, define-se o modelo:

$$
y=\left\{\begin{array}{l}
1 \text { se } y>0 \\
0 \text { caso contrário }
\end{array}\right.
$$

onde assume-se: $\mu \sim N\left(0, \sigma^{2}\right)$

\section{A Equação de Salários de Heckman}

Considere: 
Artigo original

Hegemonia - Revista Eletrônica do Programa de Mestrado em Direitos Humanos, Cidadania e Violência/Ciência Política do Centro Universitário Unieuro

ISSN: 1809-1261

UNIEURO, Brasília, número 23, Janeiro a Junho de 2018, pp. 132-159.

$W_{i}=\delta Z_{i}+\varepsilon_{1 i}$

onde $w$ é o logaritmo dos salários, $Z$ é um vetor de características pessoais, $\delta$ é um conjunto de parâmetros e $\mu$ vetor de erros aleatórios que assumem pressupostos estatísticos usuais.

Dado que a amostra sobre a proporção de emigrantes como variável dependente não é aleatória pode ocorrer viés de seletividade amostra.

$\mathrm{E}\left[W_{i} \mid y_{i} Z_{i}=1\right]=Z_{i} \delta+\mathrm{E}\left[\varepsilon_{i} \mid \mu_{i}>-\beta X_{i}\right]$

Supondo que $\varepsilon$ e $\mu$ tenham $\sim N\left(0, \sigma^{2}\right)$.

$\mu_{i}=\frac{\operatorname{cov}\left(\mu_{i}, \varepsilon_{i}\right)}{\sigma_{\mu}{ }^{2}} \mu_{i}+v$

onde $v\left(\mu_{i}, v\right)=0$.

De acordo com Heckman, se for estimada a equação (10) de rendimentos utilizando os métodos dos mínimos quadrados ordinários (MQO) os parâmetros $\delta$ seriam viesados. No entanto, se a equação de rendimentos usasse o lambda $\lambda($.) como variável explicativa, produzirá estimadores consistentes de $\delta$.

Heckman observou que o modelo poderia ser facilmente estimado utilizando o seguinte procedimento: estimar a equação de emigrantes como variável dependente sobre o vetor $X$ usando um modelo probit para obter estimativas de $\delta$ e $\mu$ i. Com base nessas estimativas constrói-se o inverso da razão de Mill. Depois, estima-se a equação de rendimentos sobre $Z$, usando o inverso da razão de Mill como variável explicativa.

De acordo Heckman (1979), mesmo que o MQO apresente alguns resultados relevantes sobre a equação de salários dos emigrantes, há sempre o risco dessas estimativas estarem viesadas devido à omissão de variáveis correlacionadas, que são capturadas pelo erro com algum regressor. Diante da presença de endogeneidade da variável explicativa estimada por MQO, causada pela a correlação entre os resíduos e esta variável, aplica-se o terceiro método de estimação, o das variáveis 
Artigo original

Hegemonia - Revista Eletrônica do Programa de Mestrado em Direitos Humanos, Cidadania e Violência/Ciência Política do Centro Universitário Unieuro

ISSN: 1809-1261

UNIEURO, Brasília, número 23, Janeiro a Junho de 2018, pp. 132-159.

instrumentais (VI), que seria a técnica estatística mais indicada para a correção deste viés, desde que seus instrumentos fossem validados.

\section{Dados, Variáveis Utilizadas e Estatísticas Descritivas}

A amostra utilizada neste estudo provém de pesquisa realizada em Palmas - TO, no segundo semestre de 2012. Os dados estão na forma de cross-section e incluem pesquisa junto a 799 entrevistados (habitantes da região de Palmas). Eles foram obtidos por meio de técnicas de interrogação, via entrevistas in loco diretamente com os entrevistados. A amostra contém informações para indivíduos entre 16 a 81 anos de idade.

A pesquisa consistiu basicamente em saber por que o indivíduo emigra. Isto será relacionado com características individuais e sociais, dele e de sua família, além de captar certos traços inerentes ao comportamento do indivíduo. Cabe ainda mencionar que outras categorias de fatores podem exercer influência sobre a decisão de migrar, sendo que eles podem estar relacionados com a herança familiar, interação social, preferências etc. $O$ trabalho incorpora informações relacionadas a esses fatores.

Primeiramente, é feita a descrição das variáveis utilizadas na modelagem estatística:

\section{Variáveis Dependentes}

(i) Insalário mensal $=$ logaritmo do salário real mensal pago por 40 horas semanal $\rightarrow$ perguntou-se ao entrevistado qual a sua renda mensal em Palmas e qual a sua renda mensal antes da mudança para Palmas; e

(ii) emigrante $=$ se o individuo é um emigrante, 1 ; caso contrário, $0 \rightarrow$ variável dummy a ser utilizada no modelo econométrico.

Variáveis Explicativas 
Artigo original

Hegemonia - Revista Eletrônica do Programa de Mestrado em Direitos Humanos, Cidadania e Violência/Ciência Política do Centro Universitário Unieuro

ISSN: 1809-1261

UNIEURO, Brasília, número 23, Janeiro a Junho de 2018, pp. 132-159.

(iii) educ $=$ números de anos de estudo $\rightarrow$ a variável educação é importante para avaliar a relação entre o tempo de estudo e a renda real do entrevistado. Ou seja, medir o impacto da variável educação na renda do emigrante.

(iv) experiência $=$ a variável experiência envolve a idade e os anos de estudo. Ela irá impactar o nível de renda em decorrência dos anos de escolaridade.

(v) bens em Palmas $=$ se o habitante possui bens na cidade, 1 ; caso contrário, $0 \rightarrow$ variável dummy que busca identificar se o entrevistado possui patrimônio adquirido após a migração. Trata-se de uma proxy para qualidade de vida (bem-estar).

(vi) ajuda_gov $=$ se o habitante recebe ajuda do governo, 1 ; caso contrário, $0 \rightarrow$ variável dummy que busca identificar se o entrevistado participa de algum programa de transferência de renda do governo federal ou estadual. Esta variável impactaria a qualidade de vida da família beneficiada.

(vii) educexper $=$ experiência vezes anos de educação $\rightarrow$ a variável busca obter informações a respeito da qualificação do emigrante. Impacta o nível de renda e a qualidade de vida da família.

(viii) tenure $=$ experiência em carteira de trabalho $\rightarrow$ busca informações sobre o tempo em que o emigrante trabalha e se ele permaneceu no mesmo ou mudou de emprego durante o período em que reside em Palmas. Essa variável impacta o nível de renda e a qualidade de vida do emigrante.

(ix) idade $=$ idade das pessoas em anos $\rightarrow$ busca caracterizar o perfil dos emigrantes. Também, como visto acima, se associa à experiência.

(x) $\operatorname{sexo}=$ se a pessoa é do sexo masculino, 1; caso contrário, $0 \rightarrow$ busca caracterizar o perfil dos emigrantes e determinar a participação no mercado de trabalho.

(xi) ocup_antes $=$ se o indivíduo tinha ocupação antes, 1 ; caso contrário, $0 \rightarrow$ variável dummy que busca informar se o indivíduo possuía ocupação antes da emigração.

(xii) casa $=$ se o indivíduo é proprietário de uma casa, 1 ; caso contrário, $0 \rightarrow$ variável dummy que busca informar sobre o patrimônio adquirido após a emigração. O patrimônio obtido impacta a qualidade de vida do emigrante. 
Artigo original

Hegemonia - Revista Eletrônica do Programa de Mestrado em Direitos Humanos, Cidadania e Violência/Ciência Política do Centro Universitário Unieuro

ISSN: 1809-1261

UNIEURO, Brasília, número 23, Janeiro a Junho de 2018, pp. 132-159.

(xiii) pess_casa $=$ há duas ou mais pessoas em casa, 1 ; caso contrário, $0 \rightarrow$ variável dummy que quantifica quantas pessoas vivem na mesma casa.

(xiv) bem-estar $=$ se o emigrante melhorou de vida, 1 ; caso contrário, $0 \rightarrow$ variável dummy que busca identificar a qualidade de vida do emigrante. Ou seja, a qualidade de vida melhorou ou não com a decisão de emigrar para Palmas.

$(\mathrm{xv})$ diversão $=$ se o indivíduo tem diversão, 1 ; caso contrário, $0 \rightarrow$ variável dummy que busca identificar se os emigrantes têm diversão. Também seria uma proxy para qualidade de vida.

(xvi) filhos $=$ se o indivíduo tem filhos, 1 ; caso contrário, $0 \rightarrow$ variável dummy associada à taxa de fertilidade dos emigrantes. Caracteriza o perfil do emigrante em relação ao crescimento populacional. (xvii) emprego $=$ se o indivíduo tem emprego, 1 ; caso contrário, $0 \rightarrow$ variável dummy que busca definir o percentual de emigrantes empregados e desempregados.

(xviii) tempo_mora_palmas $=$ tempo em que o indivíduo está morando em Palmas $\rightarrow$ mede o nível de permanência dos emigrantes em Palmas. Caracteriza o perfil do emigrante.

$($ xix) motivos_palmas $=$ se o salário foi o motivo principal da emigração, 1 ; caso contrário, $0 \rightarrow$ variável dummy que busca conhecer os motivos que levaram aos indivíduos a emigrarem para Palmas.

Voltando-se para os dados, a Tabela 1 mostra informações referentes às estatísticas descritivas das variáveis utilizadas na pesquisa. 
Artigo original

Hegemonia - Revista Eletrônica do Programa de Mestrado em Direitos Humanos, Cidadania e Violência/Ciência Política do Centro Universitário Unieuro

ISSN: 1809-1261

UNIEURO, Brasília, número 23, Janeiro a Junho de 2018, pp. 132-159.

Tabela 1 - Estatística Descritiva das Variáveis Utilizadas no Modelo

\begin{tabular}{|c|c|c|c|}
\hline Variáveis & Média & Desvio-Padrão & $\begin{array}{ll}\text { Coeficiente } & \text { de } \\
\text { Variação } & \end{array}$ \\
\hline Renda Mensal & 937,22 & $1.057,87$ & 1,13 \\
\hline Emigrante & 0,53 & 0,50 & 0,94 \\
\hline Sexo & 0,60 & 0,49 & 0,82 \\
\hline Idade & 32,00 & 11,94 & 0,37 \\
\hline Educação & 3,60 & 1,71 & 0,48 \\
\hline Experiência & 22,70 & 12,45 & 0,55 \\
\hline Bens em Palmas & 0,68 & 0,47 & 0,69 \\
\hline Ajuda do Governo & 0,81 & 0,39 & 0,48 \\
\hline Educação x Experiência & 75,22 & 53,73 & 0,71 \\
\hline Ocupação Anterior & 0,13 & 0,34 & 2,56 \\
\hline Casa & 0,49 & 0,50 & 1,02 \\
\hline Pessoas em Casa & 0,74 & 0,44 & 0,59 \\
\hline Bem-Estar & 0,77 & 0,42 & 0,55 \\
\hline Diversão & 0,78 & 0,56 & 0,71 \\
\hline Filhos & 0,56 & 0,50 & 0,89 \\
\hline Emprego & 0,77 & 0,42 & 0,55 \\
\hline Tempo de Residência em Palmas & 11,02 & 7,08 & 0,64 \\
\hline Motivo Salarial para Emigrar & 0,45 & 0,50 & 1,10 \\
\hline
\end{tabular}

Fonte: Elaborada pelos autores. 
Artigo original

Hegemonia - Revista Eletrônica do Programa de Mestrado em Direitos Humanos, Cidadania e Violência/Ciência Política do Centro Universitário Unieuro

ISSN: 1809-1261

UNIEURO, Brasília, número 23, Janeiro a Junho de 2018, pp. 132-159.

Conforme se observa acima, o número de pessoas que emigrou é superior ao de não emigrantes, $53 \%$. $^{9}$ Do total, observa-se que $60 \%$ são do sexo masculino e, obviamente, $40 \%$ do sexo feminino. Como o número de pessoas com ocupações antes de emigrar era de apenas 13\%, é oportuno levantar a suspeita da existência de viés de seleção amostral, problema que será objeto de análise adiante neste trabalho. A idade média estimada da população de Palmas, obtida a partir da pesquisa, é de 32 anos.

Com relação à variável “ajuda do governo”, verifica-se que há uma forte dominância da presença do Estado em relação aos que não recebem benefício do governo: 81\%, na média, contra 19\% (média). Verificou-se também, que a média, o desvio-padrão e o coeficiente de variação do salário real foi $\mathrm{R} \$ 937,22 ; 1.057,87 \%$; e 1,13, respectivamente. Os habitantes de Palmas são detentores de níveis de instrução baixos. Do total pesquisado, os indivíduos têm 3,6 anos de estudos, inferior à média educacional brasileira de 6 anos de estudos.

No que tange à variável experiência, os trabalhadores formais possuíam 22,7 anos (média). Quanto à distribuição da taxa de fertilidade das famílias de Palmas, os padrões retratados demonstram que 56\% das famílias possuem filhos. Na cidade de Palmas, 74\% das pessoas declaram ter pelo menos duas pessoas morando na mesma casa. Os dados da Pesquisa Nacional Por Amostra de Domicílios (PNAD) reportam que os domicílios compostos por casal com filhos registram 62,8\%, em 1992, e 49,9\%, em 2009. Parcela significativa dos emigrantes que chegam a Palmas é de habitantes que haviam migrado para outras regiões em períodos anteriores.

É interessante observar que, dentre os entrevistados, aproximadamente 49\% deles declararam serem proprietários de uma "casa". Em relação ao "tempo de residência em Palmas", dos entrevistados, temos 11,02 anos de média.

São diversas as razões que motivam a emigração. Em especial, podem-se citar as condições econômicas. Em Palmas a situação não é diferente. A decisão de emigrar foi levantada por meio de

\footnotetext{
${ }^{9}$ Considera-se emigrante os habitantes que emigraram de outros Estados para Palmas, sendo estes não goianos.
} 
Artigo original

Hegemonia - Revista Eletrônica do Programa de Mestrado em Direitos Humanos, Cidadania e Violência/Ciência Política do Centro Universitário Unieuro

ISSN: 1809-1261

UNIEURO, Brasília, número 23, Janeiro a Junho de 2018, pp. 132-159.

questões que permitiam mais de uma opção de resposta. Dos entrevistados, $45 \%$ das pessoas declararam ter sido o "salário" (Motivo para Emigrar) o fator principal que motivou a emigração.

A variável "bens em Palmas" (representa o patrimônio das pessoas que residem em Palmas) mostra que 68\% dos habitantes da cidade possuem algum tipo de bem. Outra variável, a taxa de emprego na cidade é de $77 \%$. Já no que se refere ao item "bem-estar", indica as razões para a permanência na cidade de Palmas. Neste quesito, ficou consignado que $77 \%$ dos entrevistados alcançaram o que pretendiam. Os 23\% restantes, que não apresentaram melhorias na qualidade de vida, devem-se, em geral, a questões familiares. Tal resultado guarda certa coerência com o processo migratório que, como revelaram vários entrevistados, tinha por objetivo obter recursos financeiros com vistas a uma melhor qualidade de vida.

\section{Estimação e Resultados}

A matriz de correlação simples é um importante instrumento para verificar a presença de multicolinearidade. Desse modo, verifica-se que entre as variáveis independentes não há altas correlações, o que nos lava a concluir pela inexistência de multicolinearidade, conforme pode ser visto abaixo. 
Artigo original

Hegemonia - Revista Eletrônica do Programa de Mestrado em Direitos Humanos, Cidadania e Violência/Ciência Política do Centro Universitário Unieuro

ISSN: 1809-1261

UNIEURO, Brasília, número 23, Janeiro a Junho de 2018, pp. 132-159.

Tabela 2 - Matriz de Correlação Simples

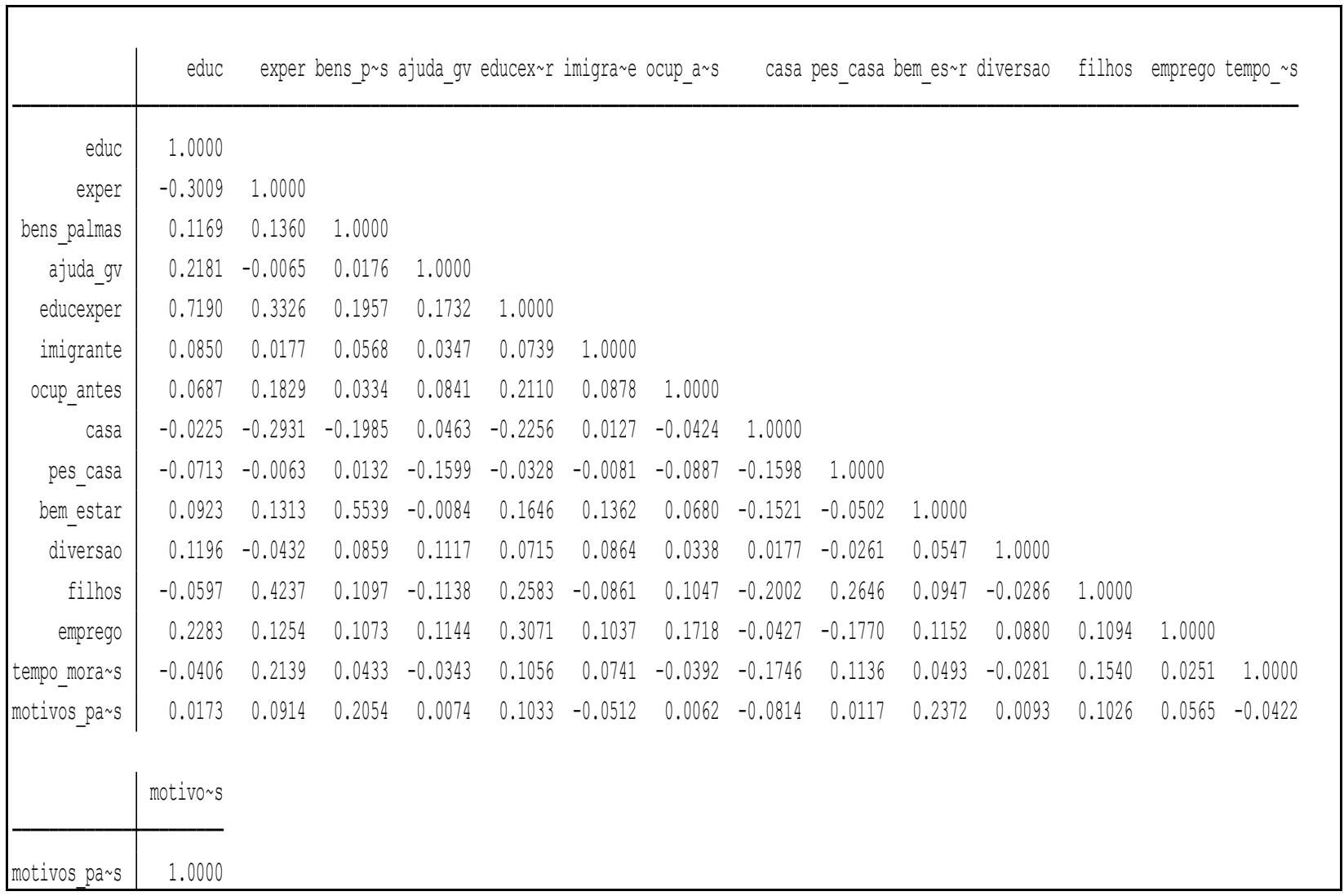

Fonte: elaborada pelos autores.

Os resultados da matriz de correlação indicaram colinearidade moderada entre as variáveis "bem-estar" e "bens em Palmas", com r = 0,5539. Há fraca correlação entre as variáveis de "experiência" e "filhos", $\mathrm{r}=$ 0,4237; "experiência" e "educação", $\mathrm{r}=$ - 0,3039; e "emprego" e "educexper" (experiência vezes educação), $\mathrm{r}=0,3071$. No entanto, estes resultados não implicam desvantagens para resultados dos outros modelos estimados.

Para investigar o impacto da "educação" sobre o processo migratório, primeiramente foi estimada uma equação de Seleção de Heckman [Heckman (1979)] com o intuito de correção do viés (outra possível fonte de viés resulta do problema de seletividade amostral) causado pela migração. O 
Artigo original

Hegemonia - Revista Eletrônica do Programa de Mestrado em Direitos Humanos, Cidadania e Violência/Ciência Política do Centro Universitário Unieuro

ISSN: 1809-1261

UNIEURO, Brasília, número 23, Janeiro a Junho de 2018, pp. 132-159.

segundo método de estimação faz uso do modelo de variáveis instrumentais. Cada um dos resultados gerados por esses dois modelos estimados e comparado com os obtidos por Mínimos Quadrados Ordinários (MQO). Na presença de endogeneidade das variáveis estimadas por MQO, deve-se à correlação entre os resíduos e a parte explicativa do modelo. Devido a isto, estimou-se um modelo com instrumentos que seja não correlacionado com o erro, mas correlacionado com a variável instrumentalizada. Este método permite isolar os efeitos da variável endógena.

As variáveis independentes são divididas em dois grupos: as explicativas de análise e as de controle. As primeiras são aquelas que são focos de análise desse estudo, isto é, as variáveis proxy de capital humano, de capital social e de capital cultural que pretende-se testar. As do segundo grupo são variáveis importantes para explicar as desigualdades no mercado de trabalho, como, por exemplo, localização geográfica, urbanização, entre outras, mas que não têm relação com as teorias que se busca testar nesse trabalho.

Análise dos Resultados

Observando os valores da estatística ₹ para o modelo de emigração, percebe-se que todas as variáveis explicativas são estatisticamente diferentes de zero ao nível de significância de 10\%. Desse modo, pode-se afirmar que cada variável explicativa influencia estatisticamente a decisão de emigrar para a cidade de Palmas.

As estatísticas da Tabela 3 mostram os resultados da equação de Seleção de Heckman para emigrantes de Palmas. A decisão de emigrar foi levantada por meio de questões que permitiam mais de uma opção de resposta. A variável escolaridade aparece significativa para o emigrante. A variável "filho" aparece com sinal positivo no modelo estimado. As razões de cunho pessoal ou familiar, diversão ou filhos, representaram, respectivamente, 35,3\% e 40,6\% das respostas.

A variável "tempo de residência em Palmas" é uma variável contínua que vai de zero a 30 anos de residência na cidade. Essa variável também é considerada uma proxy de capital cultural e de capital 
Artigo original

Hegemonia - Revista Eletrônica do Programa de Mestrado em Direitos Humanos, Cidadania e Violência/Ciência Política do Centro Universitário Unieuro

ISSN: 1809-1261

UNIEURO, Brasília, número 23, Janeiro a Junho de 2018, pp. 132-159.

social. De acordo com Borjas (1999), uma maior estada na cidade de destino tende a estimular uma maior interação social. É por meio dessa interação que o emigrante pode estabelecer contato com novas pessoas, estabelecendo conexões e incorporando a cultura dominante. Borja mostra que existe uma correlação positiva entre melhores salários e melhores qualificações dos emigrantes com maior tempo de permanência e de assimilação da cultura local. ${ }^{10}$

10 A interação social, por sua própria natureza, é um processo social e coletivo, no qual o aprendizado se dá por meio dos relacionamentos, sendo que, quanto mais intenso for o aprendizado, maior será a necessidade de interação e complementaridade. 
Artigo original

Hegemonia - Revista Eletrônica do Programa de Mestrado em Direitos Humanos, Cidadania e Violência/Ciência Política do Centro Universitário Unieuro

ISSN: 1809-1261

UNIEURO, Brasília, número 23, Janeiro a Junho de 2018, pp. 132-159.

Tabela 3 - Equação de Seleção de Heckman para Emigração

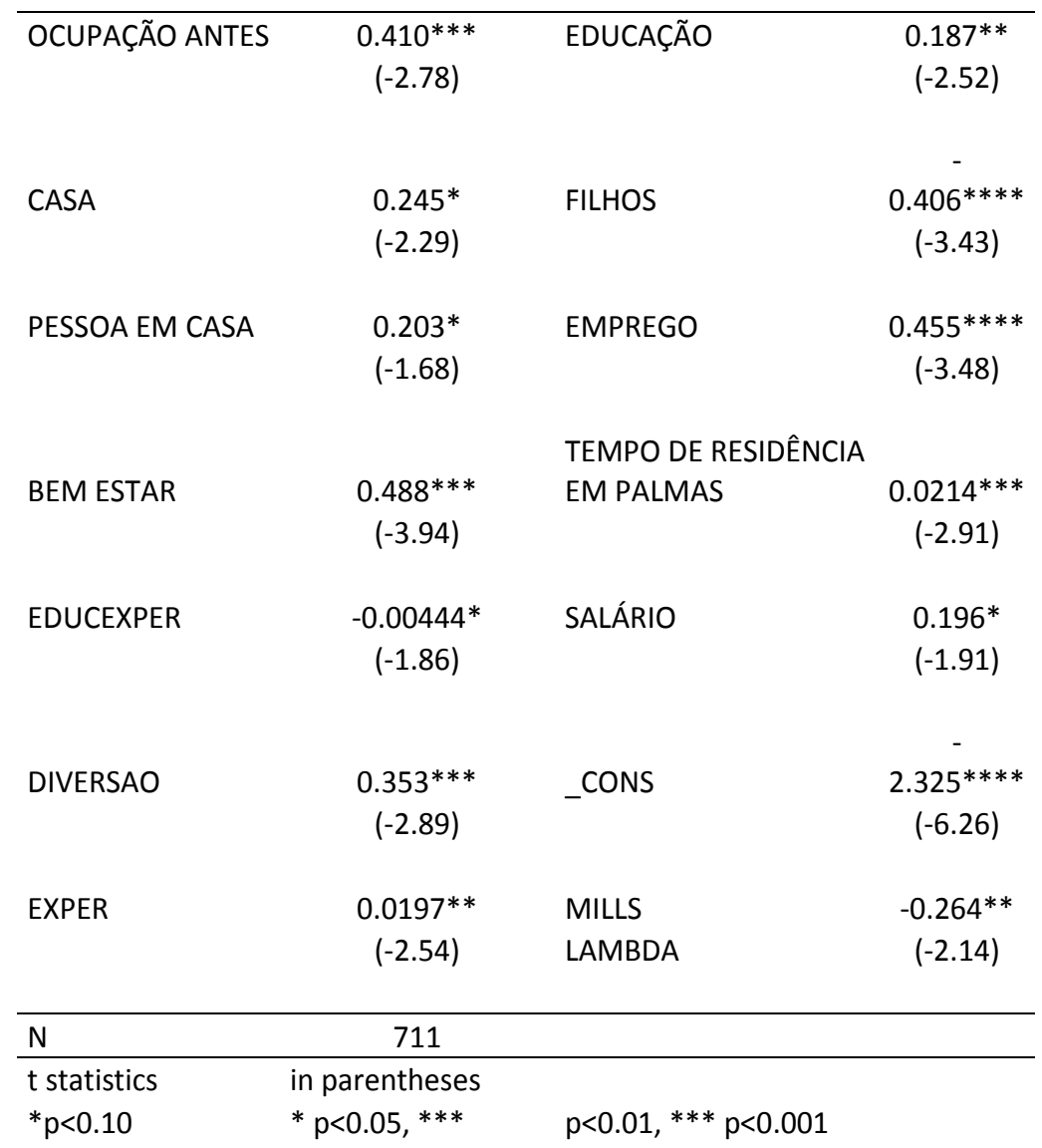

Fonte: elaborada pelos autores.

Nota: variável dependente - emigrante.

A variável causadora da emigração com maior coeficiente foi a da melhoria na condição de vida ou variável "bem-estar" (48,8\%). Percebe-se também que o emprego contribui fortemente para que o indivíduo decida emigrar. Neste caso, 45,5\% dos entrevistados aponta o "emprego" como a segunda causa principal da emigração. A decisão de emigrar está, como reportada pela Tabela 3, 
Artigo original

Hegemonia - Revista Eletrônica do Programa de Mestrado em Direitos Humanos, Cidadania e Violência/Ciência Política do Centro Universitário Unieuro

ISSN: 1809-1261

UNIEURO, Brasília, número 23, Janeiro a Junho de 2018, pp. 132-159.

relacionada diretamente à questão financeira. Para 19,6\% dos entrevistados o salário ofertado foi relevante.

A variável "mills lambda", que representa o inverso da razão de Mill, foi significativa no modelo, indicando que sua inclusão foi necessária para evitar problemas de tendenciosidade provocados pelo viés de seletividade amostral. Na estimação de Seleção de Heckman para os emigrantes, o sinal do coeficiente de Mills lambda (-0.264) mostrou-se negativo, mas estatisticamente significativo. Isto mostra que os fatores não mensuráveis podem aumentar a probabilidade do processo migratório em diminuir a taxa de salário para o ano de 2012.

Segundo Simmons (1991), as pesquisas sobre deslocamentos da população possuem análises em muitos campos estudos, sendo, portanto, enfocados com base em diversas abordagens. A educação é um dos fatores motivadores da emigração. Foi tomada como variável contínua, estendendo-se de 0 a 8 anos ou mais de estudo. Pode ser considerada a principal variável de capital humano. Os dados mostram que a cada ano a mais de estudo de um indivíduo a probabilidade de emigrar aumenta em 18,7\%. A análise probit mostrou que a "educação" tem um efeito positivo e estatisticamente significativo na participação da emigração, com o controle de outras características, tais como o número de filhos em idade escolar e emprego.

É interessante verificar que, em quase $80 \%$ dos casos, os indivíduos tinham algum contato com a cidade de destino. Este aspecto indica a clara importância da rede social como um fator motivador da migração, principalmente quando consideradas as relações familiares apontadas por grande parte dos entrevistados. Comparando os dois momentos, antes e após a migração, verificouse que no período anterior um maior número dos entrevistados estava desempregado (59,7\%). Observa-se também a proporção de pessoas com pouca experiência (1,97\%).

Dos emigrantes, 53\% declararam que, com a mudança de localidade, obtiveram ganho para a sua vida profissional. Isso é evidenciado em parte pela variável explicativa "casa". Entre os proprietários de imóveis, os emigrantes aumentam a probabilidade em 24,5\% em relação aos não emigrantes. 
Artigo original

Hegemonia - Revista Eletrônica do Programa de Mestrado em Direitos Humanos, Cidadania e Violência/Ciência Política do Centro Universitário Unieuro

ISSN: 1809-1261

UNIEURO, Brasília, número 23, Janeiro a Junho de 2018, pp. 132-159.

A Tabela 4, por seu turno, reporta os resultados das estimações com base em quatro métodos distintos: (i) OLS; (ii) Modelo de Seleção de Heckman; (iii) Variáveis Instrumentais com Dois Estágios; e (iv) Variáveis Instrumentais com GMM, para emigração na cidade de Palmas. Uma análise mais apurada da Tabela 4 sugere que os estimadores são consistentes em função dos resultados reportados por todos os métodos. Além disso, os sinais obtidos se coadunam com aqueles apresentados na literatura: os coeficientes das variáveis "educação" e "experiência" são sempre positivos.

O coeficiente da variável "educ-exper" (experiência versus educação) é positivo e os seus valores são razoáveis, coerentes com os demais valores observados na literatura do capital humano [Loureiro e Galrão (2001) e Sachsida, Loureiro e Mendonça (2004)]. Os coeficientes estimados são todos significativos aos níveis de significância de 5\%. As variávies explicativas "educação", "experiência", "educ_exper", "bens em Palmas" e "ajuda_governo" estão de acordo com a teoria do capital humano.

O Teste de Sargan é um teste de validade conjunta das variáveis instrumentais. Se a hipótese é estatisticamente confirmada, isto é, não rejeitada, os instrumentos são válidos por este critério. A hipótese que está sendo testada pelo teste de Sargan é que as variáveis instrumentais são correlacionadas com o termo de erro e corretamente excluídas da equação de estimativa principal. Diante da presença de endogeneidade das variáveis, estimou-se um modelo com instrumentos pelo método das variáveis instrumentais com dados empilhados. Todos os resultados das regressões [(3) e (4)] são do tipo dois estágios 2SLS e método de momentos generalizados-GMM. 
Artigo original

Hegemonia - Revista Eletrônica do Programa de Mestrado em Direitos Humanos, Cidadania e Violência/Ciência Política do Centro Universitário Unieuro

ISSN: $1809-1261$

UNIEURO, Brasília, número 23, Janeiro a Junho de 2018, pp. 132-159.

Tabela 4 - Equação para o Salário Mensal

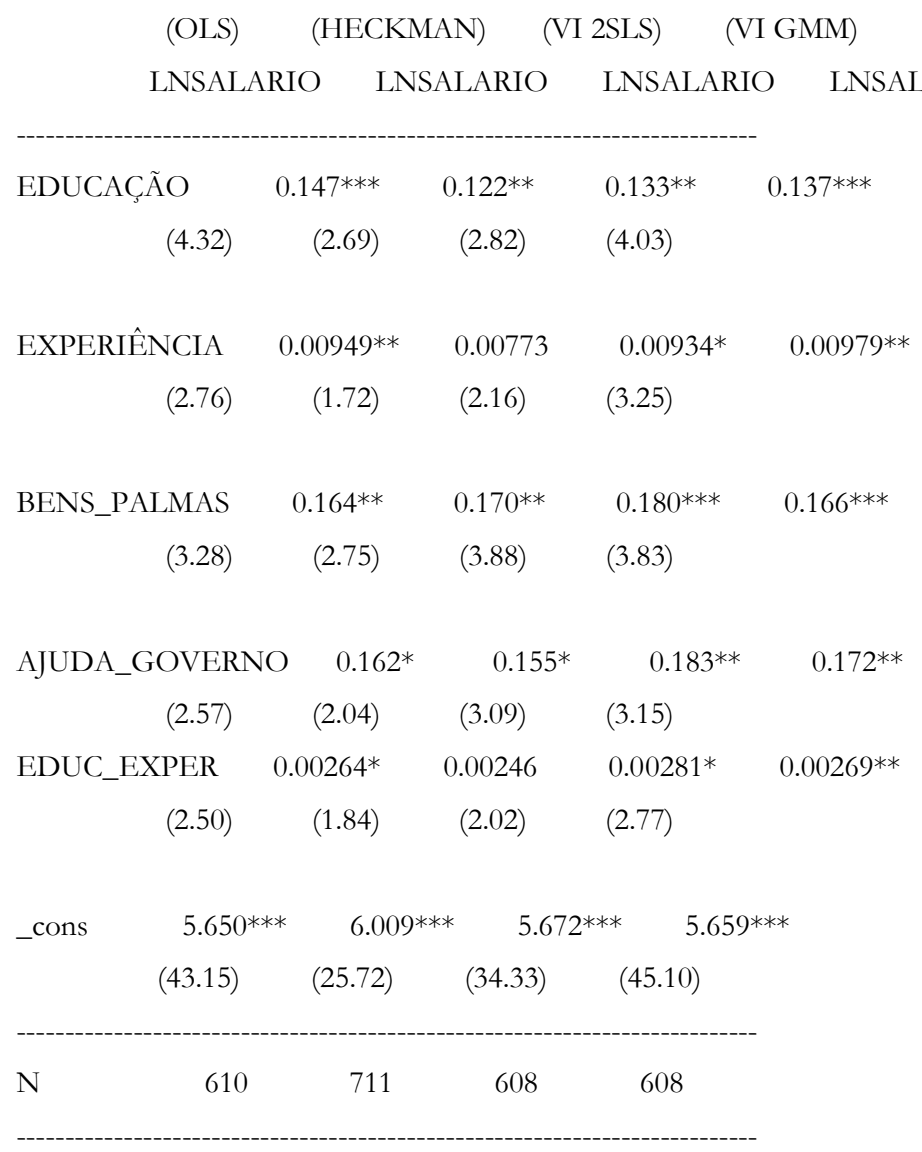

t statistics in parentheses

$* \mathrm{p}<0.05,{ }^{* *} \mathrm{p}<0.01, * * * \mathrm{p}<0.001$

Fonte: elaborado pelos autores.

Os métodos de estimação dos VI-2SLS e VI-GMM ajudam a controlar o problema de endogeneidade entre salários e escolaridade. De acordo com as estimações, obteve-se os seguintes resultados: Teste de Sargan $[\operatorname{chi} 2(3)=5.29954(\mathrm{p}=0.1511)]$; Teste de Basmann $[\operatorname{chi} 2(3)=5.267(\mathrm{p}$ $=0.1533)]$ para VI-2SLS; e Teste de Hansen $[\mathrm{J}$ chi2 $(4)=6.98263(\mathrm{p}=0.136)]$ para VI-GMM. Desse 
Artigo original

Hegemonia - Revista Eletrônica do Programa de Mestrado em Direitos Humanos, Cidadania e Violência/Ciência Política do Centro Universitário Unieuro

ISSN: 1809-1261

UNIEURO, Brasília, número 23, Janeiro a Junho de 2018, pp. 132-159.

modo, inclui-se no modelo a variável "educação" como endógena. O teste não pode rejeitar a hipótese nula de que a escolaridade pode ser tratada como exógena.

A condição da variável "bens em Palmas", que diz respeito ao patrimônio do emigrante, mantém uma relação positiva com os salários. Além disso, esta variável é estaticamente diferente de zero ao nível de 5\% de significância. Isto nos diz que, por exemplo, o indivíduo recebe, em média, 18\% a mais nos salários que o individuo que não tem patrimônio, tomando como referência o modelo de VI-2SLS. Os valores dos modelos OLS (16,4\%); Seleção de Heckman (17\%) e VI-GMM $(16,6 \%)$ são praticamente iguais, evidenciando mais uma vez a consistência dos coeficientes estimados.

Como se pode observar na Tabela 4, o impacto da "ajuda do governo" sobre os salários em todos os quatro modelos estimados mantém uma relação positiva com os salários dos trabalhadores. As estimativas dos coeficientes foram respectivamente: 16,2\%, OLS; 15,5\% Heckman; 18,3\%, VI2SLS; e, finalmente, 17,2\% pelo VI-GMM.

As equações econométricas podem ser distinguidas em quatro tipos distintos quanto à metodologia de estimação. O primeiro método de estimação trata-se de um OLS, que será utilizado para comparar com os demais modelos estimados. É comumente discutido na literatura empírica o viés pelo qual a educação pode causar sobre os salários. Isto é devido a duas razões fundamentais: pelo viés de habilidade e pelo viés de seletividade amostral.

É instrutivo comparar as equações de salários do Modelo de Seleção de Heckman e o Modelo de Regressão de Mínimos Quadrados Ordinários (OLS). Os coeficientes são bastante semelhantes, apesar da inconsistência das estimativas de mínimos quadrados. O coeficiente de escolaridade é menor na regressão de Heckman. Por isso, os salários dos mais educados tendem a não refletir o valor integral da educação no mercado. $O$ valor estimado da regressão de mínimos quadrados não leva em conta esta situação. Por isso, a estimativa do retorno à escolaridade é maior.

Quando usado OLS para ajuste da equação para $p$, o coeficiente angular foi superestimado, como previsto. Em alguns conjuntos de dados da variável de escolaridade é conhecida por estar 
Artigo original

Hegemonia - Revista Eletrônica do Programa de Mestrado em Direitos Humanos, Cidadania e Violência/Ciência Política do Centro Universitário Unieuro

ISSN: 1809-1261

UNIEURO, Brasília, número 23, Janeiro a Junho de 2018, pp. 132-159.

sujeita a erros de medição grave. Às vezes é responsável por até $10 \%$ da variação nos dados de escolaridade. No caso de as estimativas VI, não há nenhum sinal evidente de polarização. No entanto, devemos repetir os tempos experiência muito mais para ter a certeza sobre este ponto.

Vale destacar alguns aspectos das equações estimadas. Por exemplo, o coeficiente estimado dos anos de estudos da equação 1, OLS, demonstra sua importância como fator de estímulo ao salário. O acréscimo de um ano de estudo afeta positivamente, em média, 14,7\% nos salários. Podese verificar que a taxa de retorno por nível de escolaridade deste método de estimação em comparação com os outros métodos: Seleção de Heckman, 12,2\%; VI-2SLS, 13,3\%; e VI-GMM, $13,7 \%$. Isso corrobora a teoria de que se indivíduos investirem em capital humano obtêm um retorno positivo. Os valores dos coeficientes estimados para a variável "experiência” oscilaram entre 0.00773 e 0.00979. Verifica-se que não há diferenças entre estas estimações, o que indica consistência dos dados estimados para as taxas de retorno em experiência.

\section{Conclusões}

O presente artigo buscou discutir a chamada "Economia da Migração". Particularmente, buscou-se discutir o intenso movimento migratório para a cidade de Palmas, localizada no Estado de Tocantins. Deve-se recordar que Palmas é uma cidade jovem que nasceu com o novo Estado. Podese considerar que o forte fluxo migratório apresentado pela cidade está, em termos gerais, associado a esta sua característica de recém-formação.

Foram feitas ao longo do trabalho diversas discussões estatísticas e econométricas. Porém, anteriormente a essas análises, foi feita uma detalhada discussão teórica sobre a Economia da Migração, apresentando tanto os seus aspectos microeconômicos quanto macroeconômicos.

Após a discussão teórica, passou-se a detalhar o modelo estatístico a ser utilizado no artigo em seguida, passou-se aos resultados obtidos e suas respectivas análises. Basicamente, pode-se dizer que são muitas as razões que motivam a emigração. Entre os principais encontram-se as condições 
Artigo original

Hegemonia - Revista Eletrônica do Programa de Mestrado em Direitos Humanos, Cidadania e Violência/Ciência Política do Centro Universitário Unieuro

ISSN: 1809-1261

UNIEURO, Brasília, número 23, Janeiro a Junho de 2018, pp. 132-159.

econômicas. Em relação a Palmas os resultados não são diferentes. A decisão de emigrar foi levantada por meio de questão que permitia mais de uma opção de resposta. A questão salarial foi decisiva na política emigratória da Região Centro-Oeste. Dos entrevistados, 45\% das pessoas declararam ter sido o salário (Motivo para Emigrar) o fator que motivou a emigração.

Outra grande causa da emigração foi a possibilidade de melhoria na condição de vida, conforme as estatísticas construídas. O emprego também contribuiu para a decisão de emigração. Ou seja, a obtenção de trabalho em Palmas era um condicionante muito importante. Assim, pode-se concluir que a mudança migratória estudada ao longo deste trabalho pautou-se, principalmente, por questões financeiras. Em outros termos, a renda proporcionada pelo emprego, que, por sua vez, traria uma melhor condição de vida, pode ser considerada como fator crucial para a decisão de migração.

\section{Referências Bibliográficas}

Becker, G. S. Human Capital: a Theoretical and Empirical Analysis, with Special Reference to Education. Chicago: University of Chicago Press, 1993.

Borjas, George J. Economic Theory and International Migration. International Migration Review 23: 457-485, 1989.

Borjas, George J. Immigration and Welfare Magnets. Journal of Labor Economics 17: 607-637, 1999.

Fawcett, J. T. Networks, Linkages, and Migration Systems. International Migration Review 23: 671-680, 1989.

Harbison, S. F. Family Structure and Family Strategy in Migration Decision Making. in G.F. de Jong e R.W. Gardner. Migration Decision Making: Multidisciplinary Approaches to Microlevel Studies in Developed and Developing Countries. New York: Pergamon Press, 1981.

Harris, J.R. e M.P. Todaro. Migration, Unemployment and Development: a Two-Sector Analysis. American Economic Review 60: 126-142, 1970. 
Artigo original

Hegemonia - Revista Eletrônica do Programa de Mestrado em Direitos Humanos, Cidadania e Violência/Ciência Política do Centro Universitário Unieuro

ISSN: 1809-1261

UNIEURO, Brasília, número 23, Janeiro a Junho de 2018, pp. 132-159.

Heckman, James. The Common Structure of Statistical Models of Truncation, Sample Selection and Limited Dependent Variables. Annals of Economic and Social Measurement 5: 475-492, 1976.

Heckman, James. Sample Selection Bias as a Specification Error. Econometrica 47: 153-161, 1979.

Heckman, James. Varieties of Selection Bias. American Economic Review 80: 313-318, 1980.

IPEA. Migração Interna no Brasil. Comunicados do IPEA nº 61. Brasília, 2010.

Lewis, W. A. Economic Development with Unlimited Suplies of Labour. Manchester School 22: 139$191,1954$.

Loureiro, Paulo Roberto Amorim e Francisco Galrão. Discriminação no Mercado de Trabalho: uma Análise dos Setores Rural e Urbano no Brasil. Economia Aplicada 5: 519-545, 2001.

Massey, Douglas S. Social Structure, Household Strategies, and the Cumulative Causation of Migration. Population Index 56: 3-26, 1990.

Massey, Douglas S., Joaquín Arango, Graeme Hugo, Ali Kouaouci, Adela Pellegrino e J. Edward Taylor. Theories of International Migration: a Review and Appraisal. Population and Development Review 19: 431-466, 1993.

Massey, Douglas S., Rafael Alarcon, Jorge Durand e Humberto González. Return to Aztlan: the Social Process of International Migration from Western Mexico. Berkeley, Los Angeles: University of California Press, 1987.

Mincer, J. Family Migration Decisions. Journal of Political Economy 86: 749-773, 1978.

Ravenstein, E. G. The Laws of Migration. Journal of the Statistical Society of London 48: 167-235, 1885.

Piore, M. Birds of Passage: Migrant Labor in Industrial Societies. Cambridge: Cambridge University Press, 1979.

Ranis, G. e J. C. H. Fei. A Theory of Economic Development. American Economic Review 51: 533-565, 1961.

Sachsida, Adolfo e Paulo Roberto Amorim Loureiro e M. Mendonça. Um Estudo sobre o Retorno em Escolaridade no Brasil. Revista Brasileira de Economia 58: 249-265, 2004. 
Artigo original

Hegemonia - Revista Eletrônica do Programa de Mestrado em Direitos Humanos, Cidadania e Violência/Ciência Política do Centro Universitário Unieuro

ISSN: 1809-1261

UNIEURO, Brasília, número 23, Janeiro a Junho de 2018, pp. 132-159.

Simmons, A. B. Explicando la Migración: la Teoría em la Encrucijada. Estudios Demográficos y Urbanos 6: 5-31, 1991.

Sjaastad, L.A. The Costs and Returns of Human Migration. The Journal of Political Economy 70: 80-93, 1962.

Stark, O. e D. E. Bloom. The New Economics of Labor Migration. American Economic Review 75: 173178, 1985.

Stark, O. e J. E. Taylor. Relative Deprivation and International Migration. Demography 26: 1-14, 1989.

Stark, O. e J. E. Taylor. Migration Incentives, Migration Types: the Role of Relative Deprivation. The Economic Journal 101: 1.163-1.178, 1991.

Taylor, J. E. Differential Migration, Networks, Information and Risks. in O. Stark (Editor). Migration, Human Capital and Development. Greenwich, Connecticut: Jai Press Inc, 1986.

Todaro, Michael P. A Model of Labor Migration and Urban Development in Less Developed Countries. American Economic Review 59: 138-148, 1969. 